\title{
Phytoplankton population patterns in marine shrimp culture ponds with different sources of water supply.
}

\begin{abstract}
Six shrimp culture ponds of 1 ha each, located between $101^{\circ} 22^{\prime}$ E $2^{\circ} 49^{\prime} \mathrm{N}-101^{\circ} 22^{\prime}$ E $3^{\circ}$ $17 \mathrm{~N}$, were used to elucidate the effects of using eutrophic waters on phytoplankton communities. Three ponds were filled with unpolluted water, while the other three received eutrophic water. Water quality and phytoplankton populations were analyzed fortnightly over a period of 110 days to coincide with the shrimp culture cycle. In ponds with eutrophic water, the cyanobacteria (nine species) were the dominant phytoplankton group ( $>90 \%$ of the total phytoplankton density), followed by the green algae (seven species) and diatoms (six species). Ponds with originally unpolluted water were dominated by the diatoms with 18 species, followed by the cyanobacteria (six species) and one species of green algae. Shrimp production in ponds with unpolluted water was significantly higher $(4,877.4 \pm 438.5 \mathrm{~kg}$ ha- 1 when compared to $1,385.0 \pm 243.8 \mathrm{~kg}$ ha- 1 in ponds using eutrophic water. This study illustrated that initial water quality supply influenced the phytoplankton dominance, which in turn determined the aquaculture production in shrimp culture ponds.
\end{abstract}

Keyword: Water quality; Nutrients; Eutrophication. 